\title{
BMJ A national cross-sectional study on Open effects of fluoride-safe water supply on the prevalence of fluorosis in China
}

\author{
Cheng Wang, ${ }^{1}$ Yanhui Gao, ${ }^{1}$ Wei Wang, ${ }^{1}$ Lijun Zhao, ${ }^{1}$ Wei Zhang, ${ }^{1}$ Hepeng Han, ${ }^{1}$ \\ Yuxia Shi, ${ }^{1}$ Guangqian Yu, ${ }^{1}$ Dianjun Sun ${ }^{1}$
}

To cite: Wang $C$, Gao $Y$, Wang W, et al. A national cross-sectional study on effects of fluoride-safe water supply on the prevalence of fluorosis in China. BMJ Open 2012;2:e001564.

doi:10.1136/bmjopen-2012001564

- Prepublication history and additional material for this paper are available online. To view these files please visit the journal online (http://dx. doi.org/10.1136/bmjopen2012-001564").

$\mathrm{CW}$ and $\mathrm{YG}$ contributed equally to this work.

Received 27 May 2012 Accepted 21 August 2012

This final article is available for use under the terms of the Creative Commons Attribution Non-Commercial 2.0 Licence; see http://bmjopen.bmj.com

\footnotetext{
${ }^{1}$ Center for Endemic Disease Control, Chinese Center for Disease Control and Prevention, Harbin Medical University; Key Lab of Etiology and Epidemiology, Education Bureau of Hei Long Jiang Province \& Ministry of Health (23618104), Harbin 150081, China
}

Correspondence to Prof Dianjun Sun; hrbmusdj@163.com

\section{ABSTRACT}

Objective: To assess the effects of provided fluoridesafe drinking-water for the prevention and control of endemic fluorosis in China.

Design: A national cross-sectional study in China. Setting: In 1985, randomly selected villages in 27 provinces (or cities and municipalities) in 5 geographic areas all over China.

Participants: Involved 81786 children aged from 8 to 12 and 594698 adults aged over 16.

Main outcome measure: The prevalence of dental fluorosis and clinical skeletal fluorosis, the fluoride concentrations in the drinking-water in study villages and in the urine of subjects.

Results: The study showed that in the villages where the drinking-water fluoride concentrations were higher than the government standard of $1.2 \mathrm{mg} / \mathrm{l}$, but no fluoride-safe drinking-water supply scheme was provided (FNB areas), the prevalence rate and index of dental fluorosis in children, and prevalence rate of clinical skeletal fluorosis in adults were all significantly higher than those in the historical endemic fluorosis villages after the fluoride-safe drinking-water were provided (FSB areas). Additionally, the prevalence rate of dental fluorosis as well as clinical skeletal fluorosis, and the concentration of fluoride in urine were found increased with the increase of fluoride concentration in drinking-water, with significant positive correlations in the FNB areas. While, the prevalence rate of dental fluorosis and clinical skeletal fluorosis in different age groups and their degrees of prevalence were significantly lower in the FSB areas than those in the FNB areas.

Conclusions: The provision of fluoride-safe drinkingwater supply schemes had significant effects on the prevention and control of dental fluorosis and skeletal fluorosis. The study also indicated that the dental and skeletal fluorosis is still prevailing in the high-fluoride drinking-water areas in China.

\section{INTRODUCTION}

Fluoride is one of the very few chemicals that have been shown to cause significant health effects in people through drinking water.

\section{ARTICLE SUMMARY}

Article focus

- In 2008-2009, through accessing the prevalence of endemic fluorosis in China, the effects of providing fluoride-safe drinking water supply on the prevention and control of fluorosis were evaluated.

\section{Key messages}

- The subjects involved 81786 children and 594698 adults in 1985 randomly selected villages in 27 provinces (or cities and municipalities) in 5 geographic areas all over China.

- The prevalence rate of dental fluorosis as well as clinical skeletal fluorosis, and the concentration of fluoride in urine were found increased with the increase of fluoride concentration in drinking water.

- The provision of fluoride-safe water supply had significant effects on controlling the occurrence and progress of dental fluorosis and skeletal fluorosis.

Strengths and limitations of this study

- A national cross-sectional study with large representative samples was carried out on the effects of providing fluoride-safe drinking water supply for the prevention and control of endemic fluorosis in China.

- The urine fluoride concentration in adults was tested only in 2009 instead of 2008, which limited the acquirement of more information.

Low fluoride concentration in drinking water (less than $0.5 \mathrm{ppm}$ ) could cause dental caries, lack of formation of dental enamel and reduced bone mineralisation. ${ }^{12}$ In contrast, long-term consumption of drinking water containing high-fluoride concentration (more than $1 \mathrm{ppm}$ ) could cause adverse health effects ranging from mild dental fluorosis to crippling skeletal fluorosis depending on the fluoride level and period of exposure. ${ }^{1}{ }^{2}$ Fluorosis induced by exposing to high fluoride in drinking water is 
quite widespread in many countries in the world, including Argentina, Brazil, Canada, China, Eritrea, Ethiopia, Germany, India, Indonesia, Israel, Japan, Kenya, Mexico, Niger, Nigeria, Norway, Pakistan, Saudi Arabia, Senegal, South Africa, Spain, Sri Lanka, Sudan, Thailand, Turkey, Uganda, United Republic of Tanzania and the USA. ${ }^{3}$ It is now becoming a public health problem and an increasing disease burden worldwide, ${ }^{4}$ especially for the developing countries, such as China. In China, fluorosis from drinking water is a major endemic disease. A nationwide screening of high fluoride level (>1.2 mg/ 1) in drinking water in villages where fluoride-safe piped drinking water supply had or not provided was carried out from 2005 to 2007 in 231175 villages in 27 provinces all over China. In villages where fluoride-safe piped drinking water supply had been provided, water samples were randomly taken from the pipelines to test fluoride concentrations in water. In villages where fluoride-safe piped drinking water supply had not been provided, water samples were randomly collected from wells located in the east, west, south, north and centre of the villages. This investigation found that water fluoride concentration in wells or piped water supplies was higher in 51695 villages in the 27 provinces than the Chinese national standard of $1.2 \mathrm{mg} / \mathrm{l}$, where the population is more than 39 million. Most of these villages are located in the geographic areas of Northeast, Northwest and Central China. A total 47057 fluoride-safe drinking water supply schemes covering 79190 villages have been surveyed and the fluoride concentration in $14.54 \%$ of these schemes exceeded the Chinese national standard. Through this investigation, the endemic fluorosis areas in these 27 provinces had been identified.

At present, most of the studies ${ }^{5-9}$ on endemic fluorosis caused by drinking water focused on the correlation between fluoride levels in drinking water and urine as well as the prevalence of dental fluorosis and skeletal fluorosis. A high correlation between fluorosis prevalence rate and the fluoride levels in drinking water has been found. However, with the exception of China, ${ }^{5-8}$ over the past years, few reports from other countries have reported the provision of fluoride-safe drinking water supply in the fluoride-contaminated areas in large scale. In India, a report in April 2011, ${ }^{9}$ mentioned a defluorination pilot project was carried out at the level of community, but unfortunately the project came to a virtual collapse for failing to manage the project and bear the high cost in the process of maintenance in this project.

In China, since 1978, the fluoride-safe drinking water supply schemes have been built to provide fluoride-safe drinking water to the population in the high-fluoride areas and fluorosis endemic areas. Through decades' efforts of the Government, the fluoride concentrations in the drinking water in many villages have been under control to meet the government standard. On the basis of the identified endemic fluorosis areas in these 27 provinces in 2005-2007, with funds provided by the
Government, the present study was carried out in 2008 2009 to access the prevalence of endemic fluorosis, and to evaluate the effects of providing fluoride-safe drinking water supply on the prevention and control of fluorosis in China.

\section{SUBJECTS AND METHODS}

\section{Fluoride-safe water supply schemes}

For the provision of fluoride-safe water supply to villages, two technical options were adopted: (1) using the alternative low-fluoride water sources that comply with the national standard $(\leq 1.2 \mathrm{mg} / \mathrm{l})$ and (2) defluorination through the normal adsorption techniques with activated alumina or electrodialysis method. ${ }^{10}$ Two scales of fluoride-safe water supply schemes were provided: (1) large centralised piped water supply systems that can provide more than $1000 \mathrm{~m}^{3}$ of water per day or enough water for more than 10000 persons daily and (2) small centralised piped water supply schemes that can provide water to the residents below the above quantity. In the present study, the time of used correctly for the centralised piped water supply schemes were investigated, which were as the time of the switch from high-fluoride to fluoride-safe water.

\section{Study areas and contents}

In the present study, through accessing the prevalence of endemic fluorosis, the effects of providing fluoridesafe drinking water supply on the prevention and control of fluorosis were evaluated. This investigation was carried out in 231175 selected villages in 27 provinces in 5 geographic areas all over China (as presented in figure 1) in 2008-2009. It was based on outcomes of an early survey which aim was to screen on high fluoride in drinking water areas and identify the whole endemic fluorosis areas in china in 2005-2007. The study villages were divided into three categories for the investigation as follows: (1) villages where water fluoride concentration is higher than $1.2 \mathrm{mg} / \mathrm{l}$ with no fluoride-safe water supply scheme provided, and villages in mild endemic fluorosis areas with fluoride-safe water supply scheme provided; (2) villages where drinking water fluoride concentration is higher than $2 \mathrm{mg} / \mathrm{l}$ with no fluoride-safe water supply scheme provided, and villages in the moderate endemic fluorosis areas with fluoride-safe water supply scheme provided and (3) villages where drinking water fluoride concentration is higher than $4 \mathrm{mg} / \mathrm{l}$ with no fluoride-safe water supply scheme provided, and villages in the severe endemic fluorosis areas with fluoridesafe water supply schemes provided.

According to the proportion of $4 \%$ in every category, 1985 study villages were selected randomly for this study with random numbers generated by SPSS (V.13.01S; Beijing Stats Data Mining Co. Ltd, Beijing, China) in 2008-2009. In these selected villages, dental fluorosis was examined in all children aged from 8 to 12 . Besides, 6 children in every age group from 8 to 12 were 


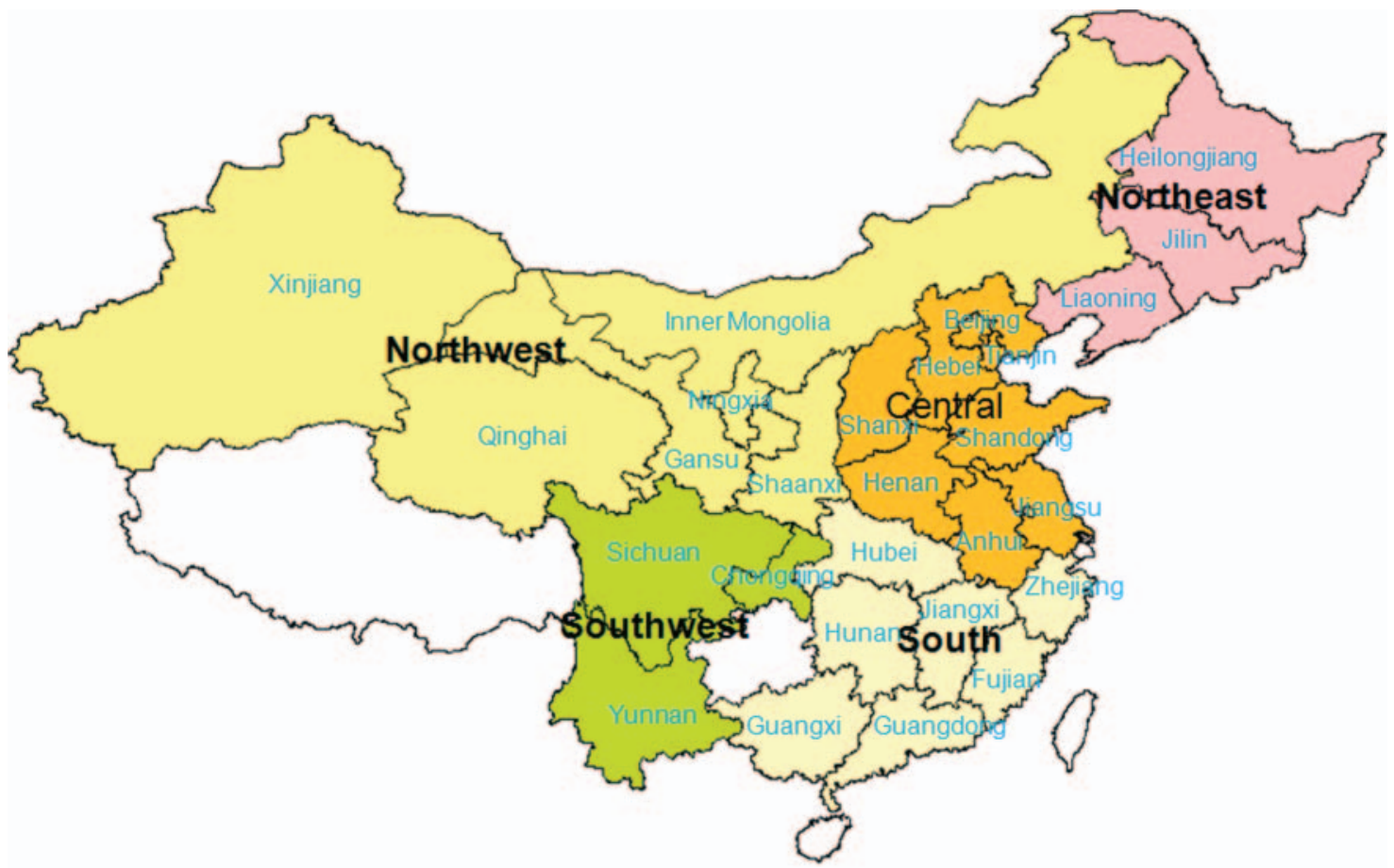

Colored areas are the distribution of $\mathbf{2 7}$ provinces in $\mathbf{5}$ geographic areas in China

Figure 1 Locations of 27 provinces in the 5 geographic areas in China.

randomly selected to test the urine fluoride concentration, and the total number of identified children in each village would be 30 . If the total numbers of children in each village are less than 30 or there were less than 6 children in each age group, all children's urine fluoride concentrations in this village were to be tested. For the test of urine fluoride level in adults, 20 adults were randomly selected among adult age group over 20 with the male-to-female ratio at $1: 1$. The urine fluoride in adults was tested only in 2009 instead of 2008. The prevalence of clinical skeletal fluorosis was investigated in all subjects over 16 years old (denoted as adults). The study protocol was approved by the Ethical Committee of the Harbin Medical University.

\section{Assessment of fluorosis endemic areas}

Endemic fluorosis areas were assessed in the following areas in this study.

The areas where water fluoride concentration is higher than $1.2 \mathrm{mg} / \mathrm{l}$, are identified as the endemic fluorosis areas, and divided into three levels according to the prevalence of fluorosis: (1) mild endemic fluorosis areas: areas where the prevalence rate of dental fluorosis is moderate, and the severe patients in the native-born residents of 8-year-old to 12 -year-old children is equal to, or less than $20 \%$, or there are mild skeletal fluorosis patients but no moderate skeletal fluorosis patients; (2) moderate endemic fluorosis areas: areas where the prevalence rate of dental fluorosis is moderate, and the severe patients in the native-born residents of 8-year-old to 12-year-old children is in the range of $20-40 \%$, or there are skeletal fluorosis patients in moderate and severe degrees, but the prevalence of severe skeletal fluorosis is equal to, or less than $2 \%$ and (3) severe endemic areas: areas where the prevalence rate of dental fluorosis is moderate, and the severe patients in the native-born residents of 8-year-old to 12-year-old children is higher than $40 \%$, or the prevalence rate of severe skeletal fluorosis is more than $2 \%$.

\section{Determination of fluoride in drinking water and urine and} the diagnosis of dental fluorosis and skeletal fluorosis

The water fluoride concentrations in two different areas were tested: (1) in areas where fluoride-safe water supply schemes had been built (FSB villages) and (2) in areas where fluoride-safe water supply scheme had not been built (FNB villages). In the FNB villages, five water samples were randomly collected in the wells located in the east, west, south, north and centre of each village, that represent the water quality of the whole village. The concentrations of fluoride in water samples were tested, and the mean value was calculated. In the FSB villages, three water samples from the pipeline of each fluoridesafe water supply scheme were randomly collected and the fluoride concentrations were tested, and the mean value was calculated. The urina sanguinis of the study subjects were collected in the morning for testing. The concentrations of fluoride in drinking water samples 
and urine samples are analysed with ion-selective electrode methods (WS/T106-1999 ${ }^{11}$ for water and WS/ T89-1996 ${ }^{12}$ for urine). Dental fluorosis was diagnosed using Dean's method ${ }^{13}$ recommended by WHO. An individual's fluorosis condition is based on the most severe form of fluorosis found on two or more teeth. An individual's dental status can be classified into six parts: normal, questionable, very mild, mild, moderate and severe. The clinical diagnosis of skeletal fluorosis followed the Diagnostic Criteria of Endemic Skeletal Fluorosis (WS 192-2008). ${ }^{14}$ An individual's skeletal fluorosis status is based on the severe form of persistent rest pain of Neck, waist and the large joints of limb, severe dyskinesia, limb deformity, and even paralysis, and can be classified into three parts: mild, moderate and severe.

\section{Quality control of project implementation}

This study was carried out by the Centre for Endemic Disease Control, Chinese Centre for Disease Control and Prevention led by the Ministry of Health. The study was planned through discussion with experts in the fields of Chinese endemic and epidemic diseases, and the Quality Control of project implementation was carried out in several aspects including: (1) according to the requirements in the Government guidelines on 'the project management scheme' and 'the project technical solutions' of national drinking water fluorosis survey, all provinces, autonomous regions and municipalities were requested to develop their own respective implementation plans in accordance with the local conditions, and to carry out this study; (2) the provincial institutions for disease prevention and control selected survey villages in accordance with the principles of randomisation, and then sent the survey plan to the concerned counties where the selected villages belonged. The institutions for disease prevention and control in the respective concerned counties were then responsible for the survey in the selected villages; (3) the concerned technicians for the analysis of fluoride concentrations in water and urine, diagnosis of dental fluorosis and clinical skeletal fluorosis, and data entry were all trained in provincial institutions, and the concerned staff at provincial levels were trained by the national experts in the national centre of endemic disease to ensure that uniform methods and standard techniques were applied in the investigation to keep the accuracy of illness diagnosis and feedback in time; (4) the provincial institutions were responsible for quality control/assessment on the analysis of fluoride concentrations in water and urine samples in all concerned county-level laboratories, and the external quality control samples were from the Center for Endemic Disease Control, Chinese Center for Disease Control and Prevention. The laboratories taking up the test of fluoride concentrations in water and urine samples were permitted to carry out the analysis tasks arranged by provincial agencies if they passed the assessment by external quality control; (5) after the provincial institutions completed the first supervision and inspection on assessment conducted in project villages, and if some problems were found/detected, corrections should be made in due course for further project implementation. At the end of the project, the consistency of project implementation, the rationality of sample collections and sampling methods, as well as the accuracy of the analysis technologies and disease diagnostic were all needed to be assessed.

\section{Statistical analysis}

Statistical analysis was carried out in all FSB and FNB villages, respectively. In FSB areas, the prevalence of fluorosis was compared in three stages, based on the length of time when the fluoride-safe water supply schemes were provided, equal to or less than 5 years, between 5 and 10 years and more than 10 years. In FNB areas (the FSB villages where fluoride concentration in water supply schemes is higher than $1.2 \mathrm{mg} / \mathrm{l}$ were considered as fluoride-safe water supply non-provided areas), the prevalence of fluorosis was compared according to the fluoride concentrations in drinking water, that is, between 1.2-2, 2-4 and higher than $4 \mathrm{mg} / \mathrm{l}$. Statistical analysis was carried out using SPSS. Data were presented as mean $\pm \mathrm{SD}$ or M-estimators by Andrew with IQR as appropriate. Data that were not normally distributed, as determined with the Kolmogorov-Smirnov test, were logarithmically transformed to obtain near normality before analysis. $\chi^{2}$ Test was used to compare categorical variables. Bivariate correlations with spearman were used to analyse the correlation between variables. All $p$ values are two-tailed and $\mathrm{p}$ value $<0.05$ were considered as significant for all statistical analyses in this study.

\section{RESULTS}

In the FSB and FNB areas, 1404 and 581 villages were selected, respectively. A total of 676484 study subjects were investigated including 81786 children and 594698 adults. The prevalence of dental fluorosis was investigated in 1876 villages covering $1318 \mathrm{FNB}$ villages and $558 \mathrm{FSB}$ villages. The prevalence of clinical skeletal fluorosis was investigated in 1622 villages consisting of 1152 FNB villages and $470 \mathrm{FSB}$ villages, respectively (in some villages, only dental fluorosis and/or clinical skeletal fluorosis were surveyed) as presented in tables 1 and 2.

The prevalence of dental fluorosis and clinical skeletal fluorosis was compared between FSB and FNB areas. The photographs taken in the surveyed villages represented the patients suffering from dental fluorosis and skeletal fluorosis (figure 2).

\section{Prevalence of dental and skeletal fluorosis in five geographic areas of China}

Prevalence rates of dental fluorosis and clinical skeletal fluorosis in FNB areas were significantly higher than that in FSB areas in five geographic parts in China as presented in table 1 . 


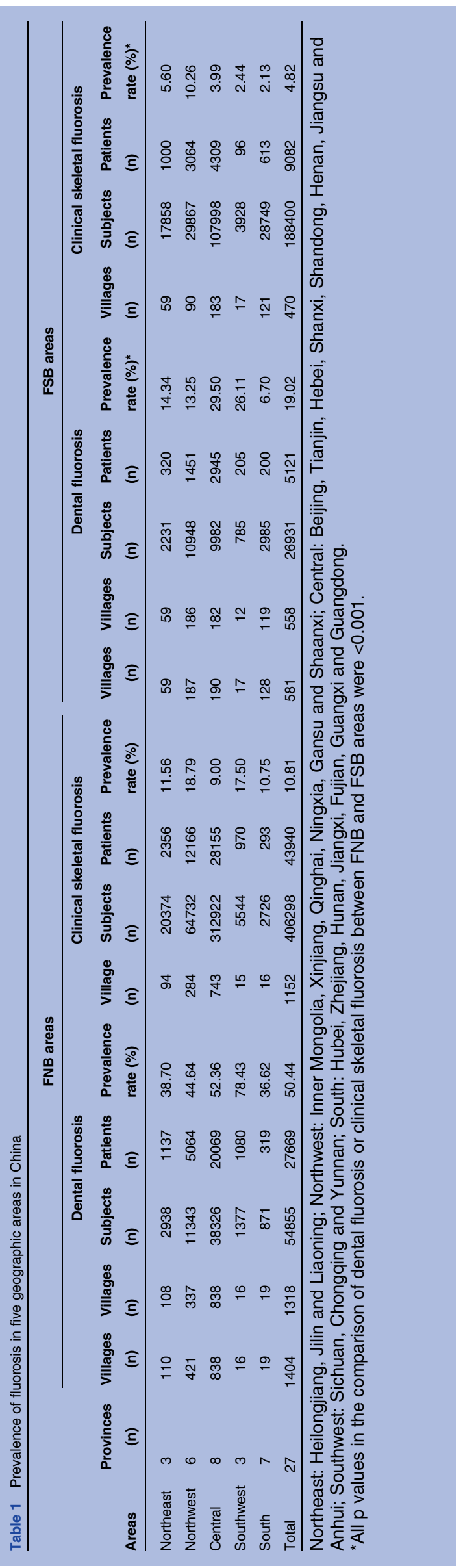

Comparison of the prevalence of dental fluorosis, skeletal fluorosis, fluoride concentrations in drinking water and urine between the FNB and FSB areas

Children aged 8-12 including 54855 in FNB areas and 26931 in FSB villages were investigated for the prevalence of dental fluorosis, and adults aged more than 16 including 406298 in FNB areas and 188400 in FSB villages were investigated for the prevalence of skeletal fluorosis. The prevalence rates of dental fluorosis and clinical skeletal fluorosis, dental fluorosis index and fluoride concentration in urine and in drinking water were significantly lower in FSB areas compared to that in FNB areas (table 2). Prevalence rates of dental fluorosis and clinical skeletal fluorosis in different ages and their prevalent degrees were all significantly lower in FSB areas than FNB areas (table 3).

\section{Relationships between the prevalence rate of dental} fluorosis, dental fluorosis index, fluoride concentrations in urine and in drinking water in FNB areas, and the period of the fluoride-safe water supply provided in FSB areas

The prevalence rate of dental fluorosis increased significantly with the increase of water fluoride concentration in FNB areas. The prevalence rates of dental fluorosis were $40.82 \%, 55.06 \%$ and $67.20 \%$ in these areas where fluoride concentration in drinking water was 1.2-2, 2-4 and $>4 \mathrm{mg} / 1$ respectively as shown in figure 3A. Significant positive correlation between the prevalence rate of dental fluorosis and fluoride concentrations in drinking water $(\mathrm{R}=0.33, \mathrm{p}<0.001)$ is presented in figure $4 \mathrm{~A}$. The prevalence rate of dental fluorosis decreased with the increase of time of the availability of fluoridesafe water in the FSB areas. The prevalence rates of dental fluorosis were $24.54 \%, 21.35 \%$ and $13.9 \%$, respectively, in the FSB villages where fluoride-safe water supply schemes were provided for equal to or less than 5 years, between 5 and 10 years and more than 10 years. And the prevalence rate of dental fluorosis in the FSB areas where the availability of fluoride-safe water supply less than 5 years $(24.54 \%)$ was lower than that in the areas where fluoride concentration between 1.2 and $2 \mathrm{mg} / \mathrm{l}$ in FNB areas (the prevalence rate of dental fluorosis is lower than $30 \%$, which is the standard could be thought as unprevalence for the dental fluorosis in China) as shown in figure $3 \mathrm{~A}$.

The dental fluorosis index and fluoride concentration in urine increased significantly with the increase of fluoride concentration in drinking water in the FNB areas. The dental fluorosis indices were $0.86,1.17$ and 1.53 and fluoride concentration in urine were 1.97(1.21, $3.00), 2.53(1.50,4.02)$ and $3.41(2.12,5.29)$, respectively, in these FNB areas where ranges of fluoride concentration in drinking water were 1.2-2, 2-4 and $>4 \mathrm{mg} / \mathrm{l}$. And there was a significant positive correlation between dental fluorosis index $(\mathrm{R}=0.34, \mathrm{p}<0.001)$, urine fluoride concentration $(\mathrm{R}=0.43, \mathrm{p}<0.001)$ in children and fluoride concentration in drinking water as presented in figure 4B,C. In the FSB areas, the fluoride concentration 


\begin{tabular}{|c|c|c|c|}
\hline & FNB areas & FSB areas & p Values \\
\hline \multicolumn{4}{|l|}{ Dental fluorosis } \\
\hline Data collected/investigated villages $(n / N)^{\star}$ & $1318 / 1404$ & $558 / 581$ & \\
\hline Subjects (children) & 54855 & 26931 & \\
\hline Age (years) & $10.07 \pm 1.44$ & $10.08 \pm 1.44$ & 0.32 \\
\hline Female sex $(\mathrm{N} / \%)$ & 25395(46.52) & $12610(46.82)$ & 0.42 \\
\hline Prevalence rate of dental fluorosis (N/\%) & $27669(50.44)$ & $5121(19.02)$ & $<0.001$ \\
\hline Dental fluorosis index $\dagger$ & 1.09 & 0.40 & \\
\hline Fluoride content in urine $(\mathrm{mg} / \mathrm{l}) \ddagger$ & $2.31(1.41,3.82)$ & $0.90(0.54,1.51)$ & $<0.001$ \\
\hline Fluoride content in water (mg/l) $\ddagger$ & $2.17(1.66,2.94)$ & $0.54(0.29,0.77)$ & $<0.001$ \\
\hline \multicolumn{4}{|l|}{ Skeletal fluorosis } \\
\hline Data collected/suvey villages $(\mathrm{n} / \mathrm{N})^{*}$ & $1152 / 1404$ & $470 / 581$ & \\
\hline Subjects (adults) & 406298 & 188400 & \\
\hline Age (years) & $42.36 \pm 16.79$ & $42.91 \pm 16.67$ & $<0.001$ \\
\hline Female sex (N/\%) & $196526(48.37)$ & $92711(49.21)$ & $<0.001$ \\
\hline Prevalence rate of clinical skeletal fluorosis (N/\%) & $43940(10.81)$ & $9082(4.82)$ & $<0.001$ \\
\hline Fluoride content in urine $(\mathrm{mg} / \mathrm{l}) \ddagger$ & $2.38(1.50,4.07)$ & $1.05(0.69,1.75)$ & $<0.001$ \\
\hline Fluoride content in water $(\mathrm{mg} / \mathrm{l}) \ddagger$ & $2.17(1.62,3.05)$ & $0.53(0.35,0.75)$ & $<0.001$ \\
\hline
\end{tabular}

in urine was significantly lower in villages where fluoride-safe drinking water supply had been provided for more than 5 years compared to that of less than 5 years. The fluoride concentration in urine were 1.00 $(0.61,1.89), 0.83(0.5,1.36)$ and $0.85(0.52,1.33)$, respectively, in areas where fluoride-safe water supply schemes had been provided for equal to or less than 5 years, between 5 and 10 years and more than 10 years. And the levels of urinary fluoride and dental fluorosis index $(1.00(0.61,1.89)$ and 0.53$)$ in the FSB areas where the availability of fluoride-safe water supply equal to or less than 5 years were lower than that in the areas where fluoride concentration between 1.2 and $2 \mathrm{mg} / 1$ in FNB areas as illustrating in figure 3B.
Relationships between the prevalence rate of clinical skeletal fluorosis, fluoride concentrations in urine and in drinking water in FNB areas and the length of time of fluoride-safe drinking water provision in FSB areas

The prevalence rate of clinical skeletal fluorosis increased significantly with the increase of fluoride concentration in drinking water in the FNB areas. As presented in figure $5 \mathrm{~A}$, the prevalence rate of clinical skeletal fluorosis increased $(7.28 \%, 11.54 \%$ and $22.64 \%)$ with the increase of fluoride concentrations in drinking water (1.2-2, 2-4 and $>4.0 \mathrm{mg} / \mathrm{l})$, respectively. And there was a significant positive correlation between the prevalence rate of clinical skeletal fluorosis and fluoride concentration in drinking water $(\mathrm{R}=0.20, \mathrm{p}<0.001)$ as illustrated in figure $4 \mathrm{D}$.
Figure 2 (A) A girl with dental fluorosis; (B) an adult with skeletal fluorosis and photos taken during the investigation.

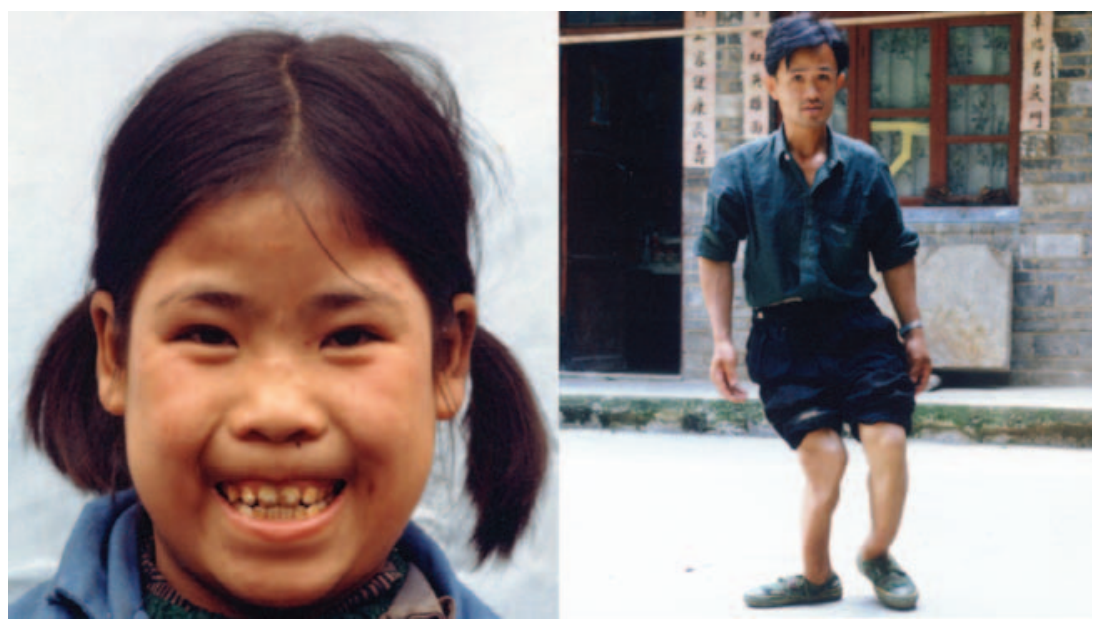


Table 3 Prevalence of fluorosis in different age groups and its prevalent degree in FNB and FSB areas

\begin{tabular}{|c|c|c|c|}
\hline & \multicolumn{2}{|c|}{ Prevalence rate (N/\%) } & \multirow{2}{*}{$\begin{array}{c}\mathbf{p} \\
\text { Values }\end{array}$} \\
\hline & FNB areas & FSB areas & \\
\hline \multicolumn{4}{|l|}{ Dental fluorosis } \\
\hline Subjects (children) & 54855 & 26931 & \\
\hline \multicolumn{4}{|l|}{ Age (year) } \\
\hline 8 & 4499 (41.97) & 722 (13.96) & $<0.001$ \\
\hline 9 & $5050(48.83)$ & 881 (16.92) & $<0.001$ \\
\hline 10 & $5613(52.12)$ & 1001 (18.92) & $<0.001$ \\
\hline 11 & $5579(53.20)$ & $1089(20.55)$ & $<0.001$ \\
\hline 12 & $6929(55.26)$ & $1428(23.03)$ & $<0.001$ \\
\hline \multicolumn{4}{|l|}{ Prevalent degrees } \\
\hline Very mild & $9862(17.98)$ & 2285 (8.48) & $<0.001$ \\
\hline Mild & 9959 (18.16) & $1777(6.60)$ & $<0.001$ \\
\hline Moderate & 5999 (10.94) & 784 (2.91) & $<0.001$ \\
\hline Severe & 1849 (3.37) & $275(1.02)$ & $<0.001$ \\
\hline \multicolumn{4}{|l|}{$\begin{array}{l}\text { Clinical skeletal } \\
\text { fluorosis }\end{array}$} \\
\hline Subjects (adults) & 406298 & 188400 & \\
\hline \multicolumn{4}{|l|}{ Age (years) } \\
\hline $16-25$ & $780(0.96)$ & $77(0.22)$ & $<0.001$ \\
\hline $26-35$ & $2143(3.15)$ & $225(0.71)$ & $<0.001$ \\
\hline $36-45$ & $6949(7.43)$ & $1192(2.75)$ & $<0.001$ \\
\hline $46-55$ & $10990(15.93)$ & $2003(5.96)$ & $<0.001$ \\
\hline $56-65$ & $12374(22.83)$ & $2714(10.82)$ & $<0.001$ \\
\hline $66-$ & $10704(26.85)$ & $2871(14.89)$ & $<0.001$ \\
\hline \multicolumn{4}{|l|}{ Prevalent degrees } \\
\hline Mild & 26491 (6.52) & $5236(2.78)$ & $<0.001$ \\
\hline Moderate & 13707 (3.37) & 3013 (1.60) & $<0.001$ \\
\hline Severe & $3742(0.92)$ & $833(0.44)$ & $<0.001$ \\
\hline
\end{tabular}

FSB areas: fluoride-safe drinking water supply schemes had been built; FNB areas: no fluoride-safe drinking water supply scheme is provided.

In the FSB areas, the prevalence rate of clinical skeletal fluorosis increased slightly and then subsequently decreased as the period of providing the fluoride-safe drinking water supply continuing to more than 10 years, but still its value was lower than that in the FNB areas where the drinking water fluoride concentration between 1.2 and $2.0 \mathrm{mg} / 1$ as shown in figure $5 \mathrm{~A}$.

The fluoride concentrations in urine were found increased significantly with the increase of fluoride concentrations in drinking water. Fluoride concentrations in urine were $1.99(1.30,3.20), 2.97(1.73,4.83)$ and $3.77(2.17,6.79)$ in areas where fluoride concentrations in drinking water were $1.2-2,2-4$ and $>4 \mathrm{mg} / \mathrm{l}$, respectively as illustrated in figure 5A. Positive correlation between urine fluoride concentrations in adults and fluoride concentration in drinking water $(\mathrm{R}=0.42, \mathrm{p}<0.001)$ is presented in figure $4 \mathrm{E}$. Urine fluoride concentrations remains unchanged in FSB areas in longer period of available fluoride-safe drinking water supply, but it is lower than those in the FNB areas where drinking water fluoride concentration is between 1.2 and $2 \mathrm{mg} / \mathrm{l}$ as shown in figure $5 \mathrm{~B}$.

\section{DISCUSSION}

Our study showed that provision of fluoride-safe drinking water supply within the government standard of
$1.2 \mathrm{mg} / \mathrm{l}$ have significant effects on the control of dental fluorosis and skeletal fluorosis, and decreasing fluoride concentrations in urine in the areas with high fluoride in drinking water. Besides, this study also provided a scientific foundation for assessing the prevalence of fluorosis in drinking water. The present study also indicated that the prevalence rates of dental fluorosis in children aged 8-12 and skeletal fluorosis in adults were 50.44 percent and $10.81 \%$, respectively, in FNB areas (the FNB areas covered the villages in the provinces where no fluoride-safe drinking water supply is provided, and the villages where fluoride-safe drinking water supply schemes were provided with the water fluoride concentrations in drinking water exceeding the government standard). On the basis of the outcomes of this study, it is estimated that 1.35 million of children aged from 8 to 12 having dental fluorosis and 3.15 million adults in the age groups of more than 16 years suffering from both dental fluorosis and skeletal fluorosis in FNB areas and in some FSB areas where the fluoride level in drinking water exceeded the government standard. These fluorosis patients were mainly distributed in the northeast, northwest and central geographic parts in China. Moreover, in these geographic areas, the endemic fluorosis is relatively more severe in the provinces of Heilongjiang, Inner Mongolia, Xinjiang, Gansu, Tianjin, Hebei, Henan, Jiangsu, Shandong, and Anhui than in other provinces. These provinces would be the priority areas when the fluoride-safe water supply schemes are provided in the future.

The relationships between levels of drinking water fluoride and urine fluoride, dental fluorosis and skeletal fluorosis have been reported in studies ${ }^{15-19}$ in Japan, Indian, Germany and South Africa. The results in the FNB areas in the present study were consistent with these former investigations that there were significantly higher prevalence rates of dental fluorosis, ${ }^{15-18}$ skeletal fluorosis ${ }^{19} 20$ and higher urine fluoride concentrations ${ }^{21}$ in areas with high fluoride concentrations in drinking water. Excessive intake of fluoride can cause the dental fluorosis and skeletal fluorosis, even with severe dyskinesia, limb deformity and even paralysis. ${ }^{14}{ }^{22-24}$ Fluoride can also damage the digestive, nervous, immune and urinary systems. ${ }^{25}$ Moreover, the fluoride can also damage the intelligence of children. ${ }^{26}{ }^{27}$ Therefore, disruption or damage of these systems can have a wide range of effects on the body.

On the basis of the severe harmful effects of fluorosis on human beings, some measures should be taken to control the occurrence and progress of fluorosis. First, the effects of pharmaceutical intervention on dental fluorosis and skeletal fluorosis could not let us feel satisfied enough, ${ }^{28}$ and severe patients finally need to carry out surgery, which result was also indeterminate; second, because the bioavailability of fluoride is generally reduced in humans when consumed milk (decreased to $70 \%)^{29}$ or a calcium (decreased to $60 \%$ )-rich diet, ${ }^{30}$ it has been highly recommended that the inhabitants of 


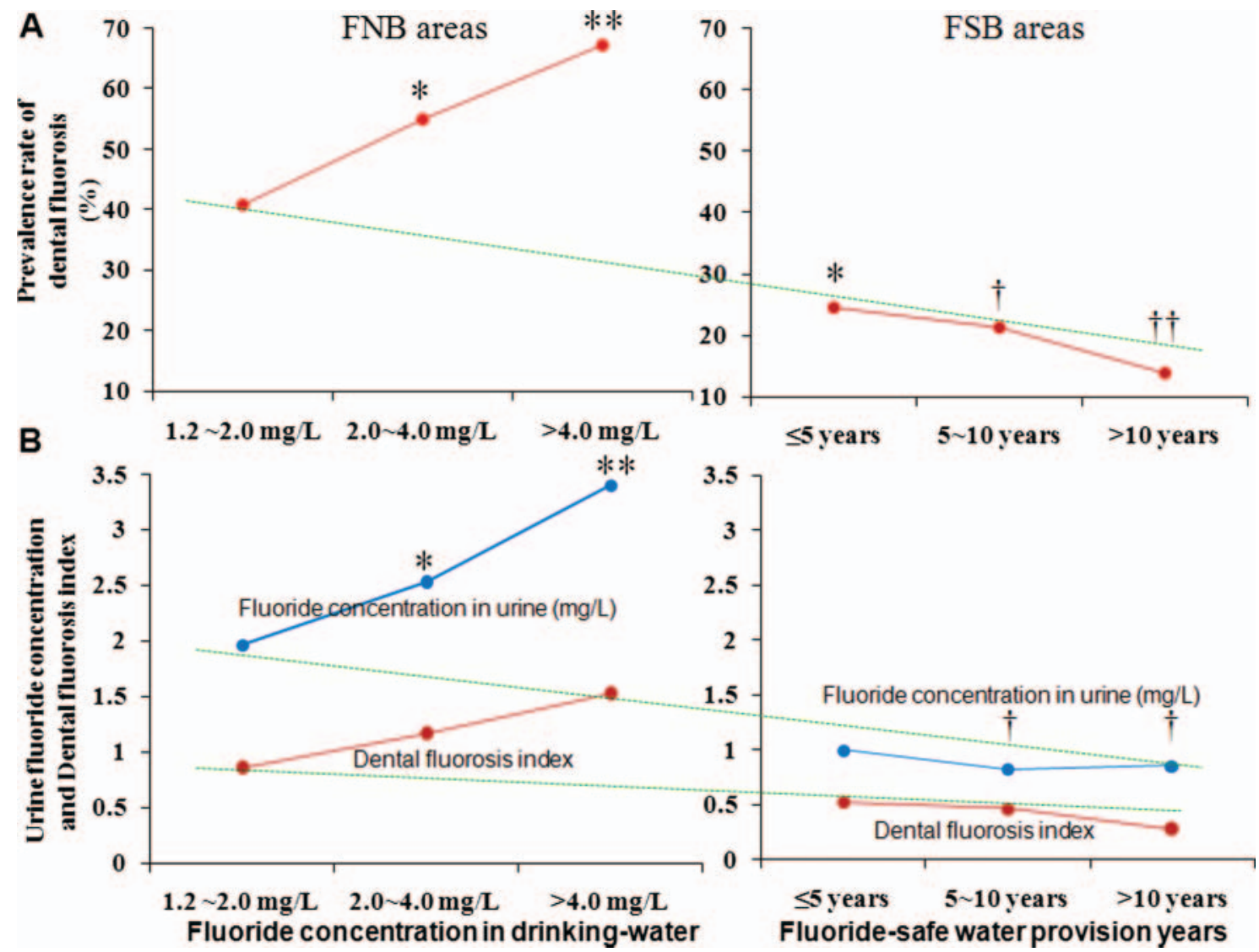

Figure 3 (A) Relationships between prevalence rate of dental fluorosis and various fluoride concentrations in the drinking water in FNB areas, and the period of fluoride-safe drinking water supply schemes built in FSB areas. (B) Relationships between the index of dental fluorosis and urine fluoride concentrations in children, and the fluoride concentration in drinking water in FNB areas and the period of fluoride-safe drinking water supply schemes built in FSB areas. * Comparing with that in the areas with fluoride concentration was $1.2-2.0 \mathrm{mg} / \mathrm{l}$ in drinking water. ${ }^{* *}$ Comparing with that in the areas with fluoride concentration was 2.0 $4.0 \mathrm{mg} / \mathrm{l}$ in drinking water. $†$ Comparing with that of fluoride-safe water supply projects built for $\leq 5$ years. $\dagger \dagger$ Comparing with that of fluoride-safe water supply projects built for $5-10$ years. All $p$ values were $<0.001$.

fluoride-contaminated areas should incorporate calciumrich foods in their routine diet. But such measures could not fundamentally solve such a problem, and it could be hard to implement in poverty areas. Therefore, changing the drinking water sources used for the inhabitants living in fluoride contaminated areas would be an appropriate and reasonable way for prevention and control of the fluorosis. In 1995, a study by Boyle et $a l^{19}$ in Gasp region, Quebec of Canada mentioned the well drilling should be in different deeps according to the F-levels in different groundwater layers through studying the relationships between the prevalence of fluorosis and F-levels in groundwater in different areas. And Boyle indicated that hydrogeochemists, hydrologists, health officials and environmental regulators should work closely together in order to efficiently eradicate the risk of skeletal fluorosis from drinking water associated with geological environments where such risks exist. Although some advices were proposed, with the exception of China, ${ }^{5-8}$ there were few relative reports in others countries on providing large-scale fluoride-safe water in the past many years. These studies ${ }^{5-8}$ in China reported the fluoride concentration in drinking water and urine, and the prevalence rate of dental fluorosis or skeletal fluorosis after the fluoride-safe drinking water supply schemes have been provided. However, most of the studies we mentioned above were carried out in one or several provinces not in the national scale, and the selected villages were seldom than the present study. In addition, these studies only reported several values of the fluoride concentration in drinking water and/or urine, and/or the prevalence rate of dental fluorosis and/or skeletal fluorosis, not including all of them. Furthermore, these above values were not compared between FNB and FSB areas, and the effects of fluoridesafe water supply on the prevalence of fluorosis had not been evaluated.

In China, the fluoride-safe drinking water supply schemes have been provided in high water fluoride areas for many years. Through years of cooperation 
A

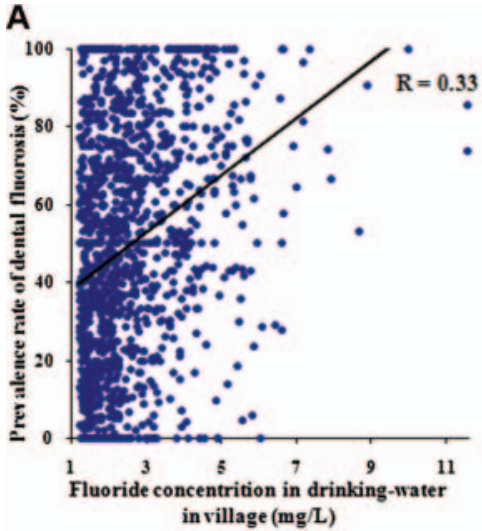

B

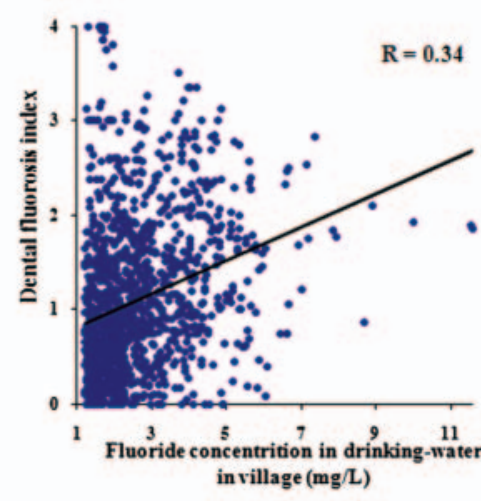

C

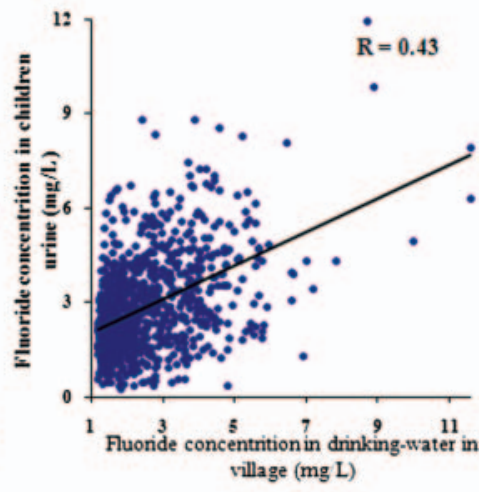

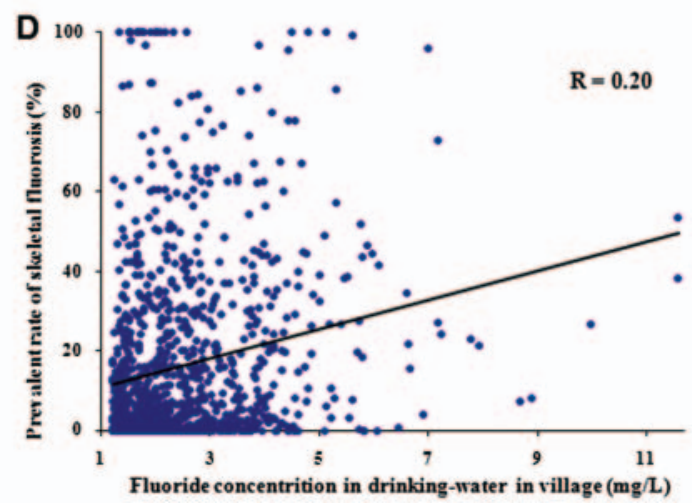

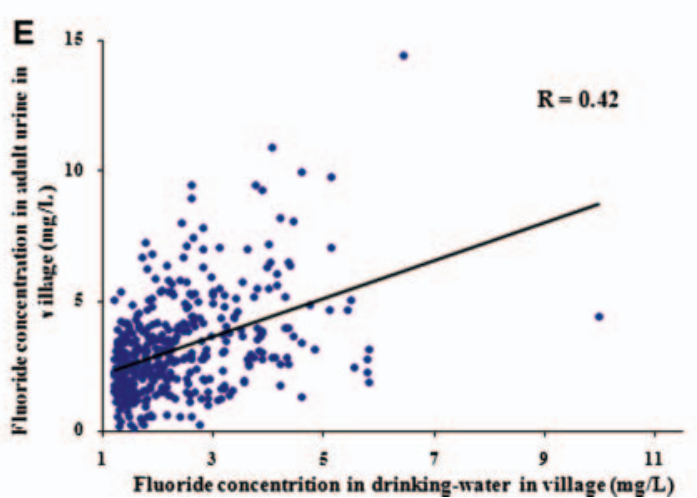

Figure 4 Correlation between fluoride concentrations in drinking water and variables including (A) prevalence of dental fluorosis, (B) dental fluorosis index, (C) fluoride concentration in children urine, (D) prevalence rate of skeletal fluorosis and (E) fluoride concentration in adult urine $(\mathrm{mg} / \mathrm{l})$. All $\mathrm{p}$ values were $<0.001$.

between various agencies, such as water resources, geology and health, rich experience has been accumulated as basis on the implementation of this study. However, some issues were observed during the study period, such as problems of difficulty in locating low fluoride level of drinking water sources and/or proper lining of wells after those wells have been drilled and proper maintenance, supervision and operation of the fluoride-safe drinking water supply schemes. In addition, some of the fluoride-safe drinking water supply schemes were found to have fluoride concentration more than $1.2 \mathrm{mg} / \mathrm{l}$. In fact, these 'fluoride-safe' drinking water supply schemes were no longer 'fluoride-safe' at all. In fact, these water schemes were providing 'non-fluoride-safe' drinking water, which is harmful to the residents' health by inducing dental fluorosis and skeletal fluorosis. The fact was that before the fluoridesafe water supply schemes were provided, the local residents were drinking water from their own tube wells with various depths, and not all tube wells had high fluoride concentration (based on the geological formation). Therefore, it is extremely important to monitor the fluoride level in all fluoride-safe drinking water supply schemes by starting from identifying the water sources to operation and maintenance, and ensure that the fluoride level in these fluoride-safe water schemes meets the government standards, and to carry out the surveillance of the prevalence of fluorosis for cross checking of the fluoride concentrations in the fluoride-safe drinking water supply schemes for long-term sustainability of supplying the fluoride-safe drinking water in FSB areas for the prevention and control of endemic fluorosis.

\section{CONCLUSIONS}

In summary, the fluoride-safe drinking water supply schemes had been provided in various localities in provinces in China for decades. The study found that providing fluoride-safe water supply had significant effects on controlling the occurrence and progress of dental fluorosis and skeletal fluorosis. The study also indicates that the dental and skeletal fluorosis is still prevailing in the high-fluoride drinking water areas in China. To control and prevent the continuous spreading of endemic fluorosis, we suggest that government's effort be given to provide the fluoride-safe drinking water supply schemes with proper operation and maintenance in all high-fluoride drinking water areas in China. 

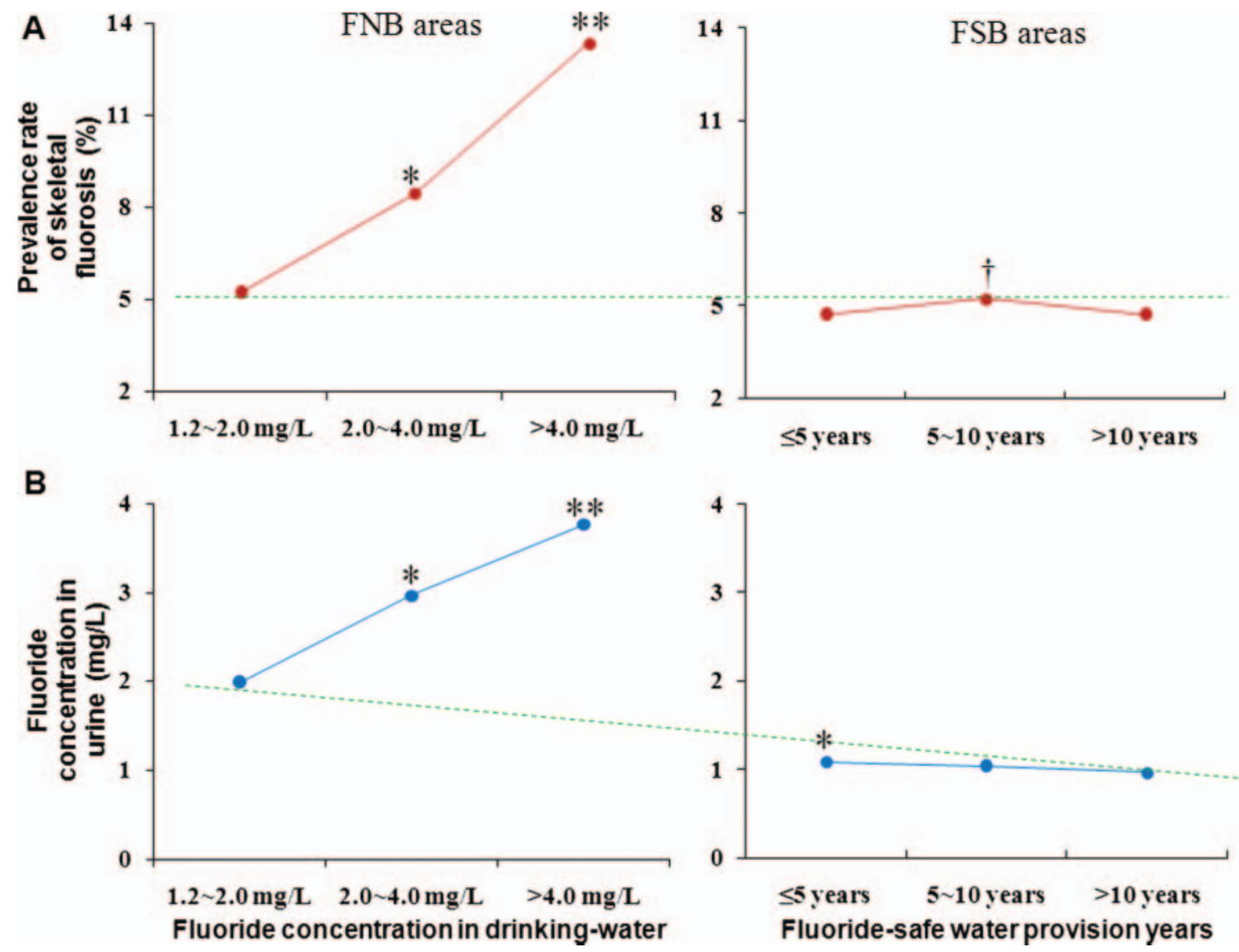

Figure 5 (A) Relationships between prevalence rate of clinical skeletal fluorosis and fluoride concentration in drinking water in FNB areas, as well as the period of fluoride-safe water supply schemes built in FSB areas; (B) the relationships between fluoride concentration in urine of adult and fluoride concentration in drinking water in FNB areas, as well as the period of fluoride reducing schemes carried out in FSB areas. * Comparing with that in the areas with fluoride concentration was $1.2-2.0 \mathrm{mg} / \mathrm{l}$ in drinking water. ${ }^{* *}$ Comparing with that in the areas with fluoride concentration was $2.0-4.0 \mathrm{mg} / \mathrm{l}$ in drinking water. $\dagger$ Comparing with that of fluoride-safe water supply projects built for $\leq 5$ years. All $p$ values were $<0.001$.

Acknowledgements We are grateful to the generous support by many researchers and medical professionals from the various Centers for Endemic Disease Control in the 27 provinces, autonomous regions and municipalities and for their continuous efforts and collaboration during this study. We wish to acknowledge the close cooperation of many fluorosis patients who allowed us to do the examination and checking up for this study.

Contributors DS contributed to the conception and design of the study. CW and $Y G$ contributed to the analysis of data. CW, YG, WW, LZ, WZ, HH, YS, GY, and DS have contributed to the acquisition and interpretation of data, drafting the article and revisions for important intellectual content and final approval of the version to be published.

Funding This work was supported by the Chinese government for Endemic Disease Control in 2008-2009 years.

Competing interests None.

Ethics approval Ethical approval was provided by the Ethical Committee at the Harbin Medical University.

Provenance and peer review Not commissioned; externally peer reviewed.

Data sharing statement There are no additional data available.

\section{REFERENCES}

1. World Health Organization. Guidelines for drinking water quality. Recommendations, vol 1. http://www.who.int/ water_sanitation_health/dwq/gdwq3rev/en/ (accessed 10 Nov 2011).
2. Jha SK, Mishra VK, Sharma DK, et al. Fluoride in the environment and its metabolism in humans. Rev Environ Contam Toxicol 2011;211:121-42.

3. World Health Organization. Fluoride in Drinking-water. http://www. who.int/water_sanitation_health/publications/fluoride_drinking_water/ en/index.html (accessed 10 Nov 2011).

4. Fewtrell L, Smith S, Kay D, et al. An attempt to estimate the global burden of disease due to fluoride in drinking water. $J$ Water Health 2006;:4:533-42.

5. Zhu C, Bai G, Liu X, et al. Screening high-fluoride and high-arsenic drinking waters and surveying endemic fluorosis and arsenism in Shaanxi province in western China. Water Res 2006;40:3015-22.

6. Liang $C$. Evaluation on the effects of water defluoridation measures in China. J Hygiene Res 1998:27:16-28. (Article in Chinese)

7. Wu J, Zhang J, Chen Z, et al. Survey on children's dental fluorosis and fluoride content in urine after defluridation to improve drinking water. J Hygiene Res 2000;29:218-20. (Article in Chinese)

8. Collaboration Group of National Endemic Fluorosis Surveillance. Report on the surveillance of endemic fluorosis of drinking water type in China in 2005 and 2006. Chin J Endemiol 2009;28:175-80.

9. Bikash KP, Rath B. The Raipali experience. 2011; http://www. rcdcindia.org/raipalli.pdf (accessed on 15 Jun 2011).

10. Mohapatra M, Anand S, Mishra BK, et al. Review of fluoride removal from drinking water. J Environ Manage 2009;91:67-77.

11. Ministry of Health of the People's Republic of China. Method for Determination of Fluoride in Drinking Water of Endemic Fluorosis Areas (WS/T 106-1999), 1999.

12. Ministry of Health of the People's Republic of China. Determination of Fluoride in Urine-ion Selective Electrode Method (WS/T 89-1996), 1996.

13. Dean HT. The investigation of physiological effects by the epidemiological method. In: Moulton FR, ed. Fluorine and dental 
health. Washington, DC: American Association for the Advancement of Science, 1942:23-31.

14. Ministry of Health of the People's Republic of China. Diagnostic Criteria of Endemic Skeletal Fluorosis (WS 192-2008), Issued in 2008. http://www.wwwstandard.cn/index.php?doc-view-22507.html (accessed on 23 Jul 2011)

15. Fantong WY, Satake H, Ayonghe SN, et al. Geochemical provenance and spatial distribution of fluoride in groundwater of Mayo Tsanaga River Basin, Far North Region, Cameroon: implications for incidence of fluorosis and optimal consumption dose. Environ Geochem Health 2010;32:147-63.

16. Yadav JP, Lata S, Kataria SK, et al. Fluoride distribution in groundwater and survey of dental fluorosis among school children in the villages of the Jhajiar District of Haryana, India. Environ Geochem Health 2009;31:431-8.

17. Shomar B, Müller G, Yahya A, et al. Fluorides in groundwater, soil and infused black tea and the occurrence of dental fluorosis among school children of the Gaza strip. J Water Health 2004;2:23-35.

18. Grobleri SR, Louw AJ, van Kotze TJ. Dental fluorosis and caries experience in relation to three different drinking water fluoride levels in South Africa. Int J Paediatr Dent 2001;11:372-9.

19. Boyle DR, Chagnon M. An incidence of skeletal fluorosis associated with groundwaters of the maritime carboniferous basin, Gasp region, Quebec, Canada. Environ Geochem Hlth 1995;17:5-12.

20. Choubisa SL, Choubisa L, Choubisa D. Osteo-dental fluorosis in relation to age and sex in tribal districts of Rajasthan, India. J Environ Sci Eng 2010;52:199-204.
21. Yadav JP, Lata S. Urinary fluoride levels and prevalence of dental fluorosis in children of Jhajjar District, Haryana. Indian J Med Sci 2003;57:394-9.

22. Kumar H, Boban M, Tiwari M. Skeletal fluorosis causing high cervical myelopathy. J Clin Neurosci 2009;16:828-30.

23. Shashi A, Kumar M, Bhardwaj M. Incidence of skeletal deformities in endemic fluorosis. Trop Doct 2008;38:231-3.

24. Everett ET. Fluoride's effects on the formation of teeth and bones, and the influence of genetics. J Dent Res 2011;90:552-60.

25. National Research Council. "Fluoride in Drinking Water: A Scientific Review of EPA's Standards" 2006; http://www.nap.edu/catalog.php? record_id=11571. (accessed $5 \mathrm{Dec} 2011$ ).

26. Ding YP, Gao YH, Sun HX, et al. The relationships between low levels of urine fluoride on children's intelligence, dental fluorosis in endemic fluorosis areas in Hulunbuir, Inner Mongolia, China. $J$ Hazard Mater 2011;186:1942-6.

27. Wang SX, Wang ZH, Cheng XT, et al. Arsenic and fluoride exposure in drinking water: children's IQ and growth in Shanyin county, Shanxi province, China. Environ Health Persp 2007;115:643-7.

28. Sang ZC, Zhou W, Zhang ZJ, et al. X-ray analysis on 114 patients with moderate endemic skeletal fluorosis by treatment of Guo's Chinese herbal. Zhongguo Gu Shang 2010;23:379-82. (Article in Chinese)

29. Ekstrand J, Ehrnebo M. Influence of milk products on fluoride bioavailability in man. Eur J Clin Pharmacol 1979;16:211-15.

30. Shulman ER, Vallejo M. Effect of gastric contents on the bioavailability of fluoride in humans. Pediatr Dent 1990;12:237-40. 